\title{
UCRL-TR-217053
}

LAWRENCE LIVERMORE N A T IO N A L LABORATORY
Phase Effects on Mesoscale Object X-ray Attenuation Radiographs

H. E. Martz, Jr., M. B. Aufderheide, A. Barty, S. Hau-Riege, S. K. Lehman, B. J. Kozioziemski, D. J. Schneberk

November 14, 2005 
This document was prepared as an account of work sponsored by an agency of the United States Government. Neither the United States Government nor the University of California nor any of their employees, makes any warranty, express or implied, or assumes any legal liability or responsibility for the accuracy, completeness, or usefulness of any information, apparatus, product, or process disclosed, or represents that its use would not infringe privately owned rights. Reference herein to any specific commercial product, process, or service by trade name, trademark, manufacturer, or otherwise, does not necessarily constitute or imply its endorsement, recommendation, or favoring by the United States Government or the University of California. The views and opinions of authors expressed herein do not necessarily state or reflect those of the United States Government or the University of California, and shall not be used for advertising or product endorsement purposes.

This work was performed under the auspices of the U.S. Department of Energy by University of California, Lawrence Livermore National Laboratory under Contract W-7405-Eng-48. 


\section{Phase Effects on Mesoscale Object X-ray Attenuation Radiographs}

H. E. Martz, Jr., M. B. Aufderheide, A. Barty, S. Hau-Riege, S. K. Lehman, B. J. Kozioziemski, and D. J. Schneberk

Digital $\mathrm{x}$-ray radiography and computed tomography methods are commonly used to characterize mesoscale objects ( $\mathrm{mm}$ size objects with $\mu \mathrm{m}$ size features). However the ability of these methods to provide high spatial resolution images is dependent, in part, on object recovery algorithms that account for phase effects [1]. The objective of this work is the development and validation of algorithms to model phasecontrast effects observed in $\mathrm{x}$-ray radiographic systems, and to use these algorithms for quantitative object recovery. This work has three distinct tasks. First, we are modifying HADES [2,3] to model x-ray phase contrast and are investigating whether multislice techniques within the object are needed to fully capture the physics seen in $\mathrm{x}$ ray data. Second, we are developing object recovery approaches. Third, we are validating these simulations against $\mathrm{x}$-ray systems using well-known objects. At the end of this $R \& D$, we will have a set of validated $\mathrm{x}$-ray forward modeling codes including the effects of phase and an understanding of the current object recovery methods limitations.

In the past year, we have fully integrated the Fresnel-Kirchoff diffraction theory into HADES modeling. This required an upgrade of HADES' calls to the FFTW $^{1}$ fast Fourier transform library. This work is now complete. In addition, we have merged into HADES the LBNL photoelectric absorption and phase cross sections with the LLNL Evaluated Photon Data Library cross sections for Compton and Rayleigh scattering, as well as Pair Production. Compton Scattering becomes a sizeable part of the absorption cross section for low-atomic-number materials at high x-ray energies. Representative results from the new HADES code are shown in Figure 1.

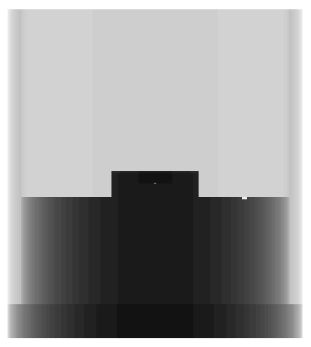

(a)

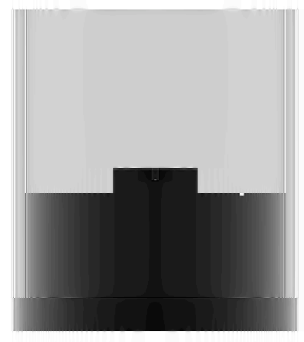

(b)
Figure 1 HADES simulated radiographs of a cylindrical reference standard without (a) and with (b) x-ray phase. Note x-ray phase effects create the well known bright and dark edges

The resolution of x-ray images has improved to the point that spatial resolution and object dimensions could theoretically result in the wave diffraction effects within the object becoming significant. We studied this possibility numerically using four simulation codes that incorporate $\mathrm{x}$-ray phase effects. We refer to them as (1) The paraxial approximation multi-slice simulation code; (2) A Kirchoff propagation simulation code; (3) A Mie type analytical simulation code [4]; and (4) HADES. The paraxial approximation code with and without a multislice method and the Kirchoff propagation code were used to model at worstcase $\mathrm{x}$-ray energies of $\sim 8-\mathrm{keV}$ and compared these results to empirical data. The conclusion, based upon the results of the validated simulation codes, is that diffraction effects within the object are insignificant for $>=8 \mathrm{keV}$ $\mathrm{x}$-rays data with $\sim 1-\mu \mathrm{m}$ spatial resolution and for objects up to $10 \mathrm{~mm}$ (Figure 2).

A number of approaches have been developed for recovering phase from mesoscale radiographs. A certain class of phase recovery techniques employs differential equation solvers (Multi-Grid techniques) to solve for the electron density. We have implemented the most straightforward technique, which applies to the case of weak absorption and uniform irradiance. We have applied Multi-Grid techniques to both synchrotron and non-

${ }^{1}$ Fastest Fourier Transform of the West 
synchrotron data. An example of results for a point-projection non-synchrotron system (Xradia Micro-XCT) is shown in Figure 3. Comparisons with simulated data have shown the range of these techniques to be limited to cases of $90 \%$ transmission or better for simple geometric objects. Most of our data are on order of $20 \%$ transmission for objects with complex geometry and thus this object recovery method is not very useful for most of our data. Furthermore, we have found these techniques to be sensitive to clutter in the scintillator and small aberrations in the optics used to couple the light from an x-ray scintillator to a CCD camera.

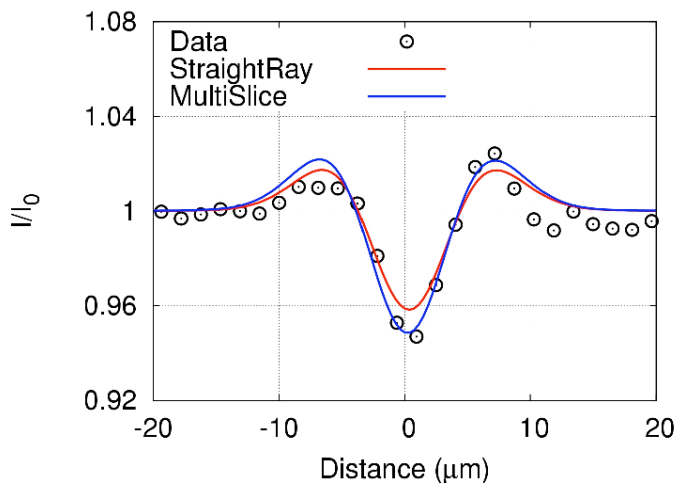

(a)

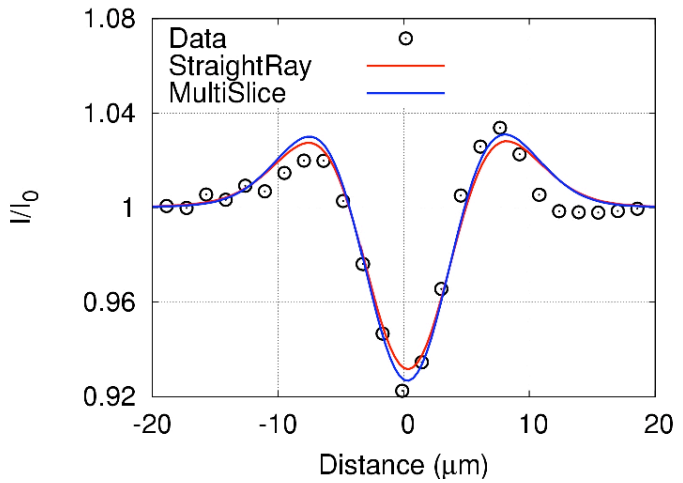

(b)

Figure 2. Lineout plots of the single (a) and double (b) $\mathrm{C}$ fiber projections. The measured data (open circles) were collected by a $\mathrm{Cu}$-anode source and a direct detection CCD camera.[5] The simulated straight ray (red curve) and the multislice (blue curve) projections have been convolved with a single Gaussian line-spread function with a Gaussian sigma value of 3.6 and 4.0 for the single and double fiber data, respectively. Note the very good agreement between both simulated results and the empirical data.

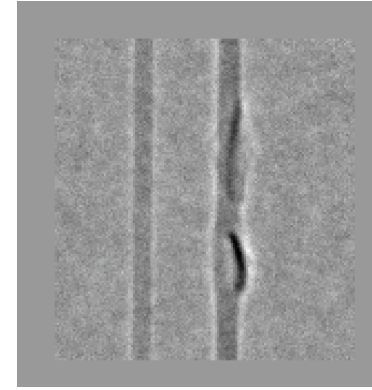

(a)

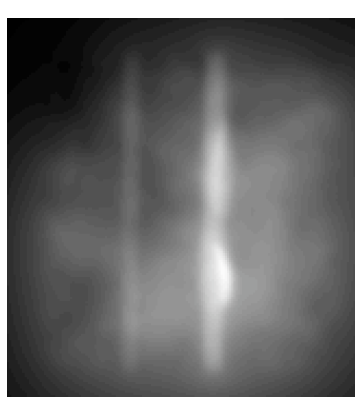

(b)
Figure 3 Digital radiograph of the two non-aligned $\mathrm{C}$ fibers acquired at $99 \mathrm{kV}$ and $41 \mu \mathrm{A}$ and pixel size of $0.6 \mu \mathrm{m}$ at the object center (a). Electron density (related to $\mathrm{x}$-ray phase) results (b) from application of the weak absorption and uniform irradiance method on the digital radiograph shown in (a).

The 'multi-slice' phantom was fabricated to contain either 6- $\mu \mathrm{m}$ outer-diameter carbon fibers or 4- $\mu \mathrm{m}$ outer-diameter tungsten wires in various pre-selected configurations. The fibers or wires are attached to a base and slide that is adjustable in separation length from 2 to $10.2 \mathrm{~mm}$. Three $5-\mu \mathrm{m}$ carbon fibers were inserted into the multi-slice phantom and the phantom was oriented such that the fibers were vertical in the digital radiographs [see Figure 3(a)] and rotation could be used to align the two carbon fibers that were separated by $10.2 \mathrm{~mm}$.

\section{References}

[1] Martz Jr., H. E., and G. F. Albrecht, (2003), Proceedings of: Machines and Processes for Micro-scale and Meso-scale Fabrication, Metrology, and Assembly, ASPE 2003 Winter Topical Meeting, Gainesville, FL, January 2223, pp.131-141.

[2] Aufderheide, M. B., D. M. Slone, and A. E. Schach von Wittenau (2000), Review of Progress in Quantitative Nondestructive Evaluation, 20A, AIP Conference Proceedings 557, pp. 507-513.

[3] Aufderheide, M.B., Barty, A., and Martz, H.E. (2004), Review of Progress in Quantitative Nondestructive, 24A AIP Proceedings 760, pp. 663670.

[4] Hau-Riege, S. P., 2005, accepted for publication in Appl. Opt.; Lawrence Livermore National Laboratory, Livermore, CA, UCRL-JRNL-211307.

[5] Martz, Jr., Harry E., Bernard J. Kozioziemski, Sean K. Lehman, Stefan Hau-Riege, Daniel J. Schneberk and Anton Barty, "Validation of Radiographic Simulation Codes Including X-ray Phase-Effects for Mesoscale Objects," to be published. 